\title{
COMUNICADORES COMUNITARIOS COMO NARRADORES DE TERRITORIOS HABITADOS EN LA PERIFERIA DE RIO DE JANEIRO
}

Eunice Muruet Luna ${ }^{i}$

\section{INTRODUCCIÓN}

Este texto es una tentativa de contar una historia contenida en varias historias, un intento de traducir la vorágine de acontecimientos, encuentros e informaciones que fueron entretejiéndose en mis experiencias - la académica y la de vida - durante el curso de Maestría en Educación en la Universidad del Estado de Rio de Janeiro entre 2012 y 2014. En este periodo compartí formación y procesos de investigación junto con profesores/investigadores del grupo Infancia y Cultura Contemporánea, mismo que pertenece a la línea de investigación Infancia, juventud y educación de la universidad antes mencionada. Tales experiencias, a partir de la especificidad de ser extranjera en diversos niveles (Como becaria mexicana en un contexto universitario brasileiro, como investigadora en un territorio de la ciudad que no me era familiar, como comunicadora en un contexto de comunicación comunitaria, como adulta investigando temas relacionados con infancia, por decir algunos), me llevaron a un conjunto de reflexiones sobre la alteridad en la investigación dentro de las ciencias humanas; las posibilidades y matices para la apertura del diálogo intercultural a través de la comunicación comunitaria — que funge a manera de puente-, así como el lugar que ocupa aquel que ejerce la comunicación comunitaria como posición política y la importancia del sujeto social en la construcción del discurso desde espacios comunicativos y de memoria no hegemónicos. Todos estos temas se entrelazaron para formar parte de mi disertación titulada Los lugares de la infancia en procesos de comunicación comunitaria, la cual tomó al periódico comunitario O Cidadão da Maré como experiencia. ii Dichas reflexiones se basaron en un método de origen fenomenológico, considerado como "un conjunto de conocimientos e ideas que, si son tomados como ejemplo, constituyen tanto una fuente como una base metodológica para presentar las prácticas de investigación en ciencias humanas" (Ayala, 2008).

\section{MARÉ: UN POCO DE HISTORIA}

"Pasé mi infancia en medio de los palafitos, jugando en los puentes de madera que pasaban encima del agua. Agua para usar solo teníamos cada ocho días. La cosa era cargar latas de agua en la cabeza y pasar las noches despierto para llenarlas"

(Testimonio de un habitante de la favela Baixa do Sapateiro, Maréiii) 
Localizado en la periferia de la Zona Leopoldina en la ciudad de Rio de Janeiro, ${ }^{\text {iv }}$ entre la Avenida Brasil, Linha Vermelha y Linha Amarela, arterias de vital importancia para la circulación en dicha ciudad, el conjunto de favelas de Maré está en continua transformación: desde su ocupación por más de 40 aldeas indígenas alrededor de la Bahía de Guanabara en el período de la llegada de los portugueses, ${ }^{v}$ los primeros asentamientos en el Morro de Timbau, las ocupaciones realizadas por las personas removidas de otras favelas y también debido a la migración interna, en su mayoría de brasileiros venidos del nordeste y del interior de Rio de Janeiro que llegaron con la esperanza de encontrar oportunidades de trabajo y una mejor calidad de vida en la ciudad, como consecuencia de la introducción de las relaciones capitalistas de producción en las zonas agrícolas de Brasil, que generaron precariedad y cuando la tierra faltó (y la necesidad de subsistencia persistía), la construcción de las llamados palafitos (casas con base de madera construidas sobre las aguas de la Bahía de Guanabara), hasta la implantación en 1979 del Proyecto Rio, por parte del Banco Nacional de Habitación, que preveía una intervención en un perímetro de 27 kilómetros con el objetivo de sanear la Bahía y de crear los espacios para abrigar a la población de baja renta. ${ }^{\text {vi }}$

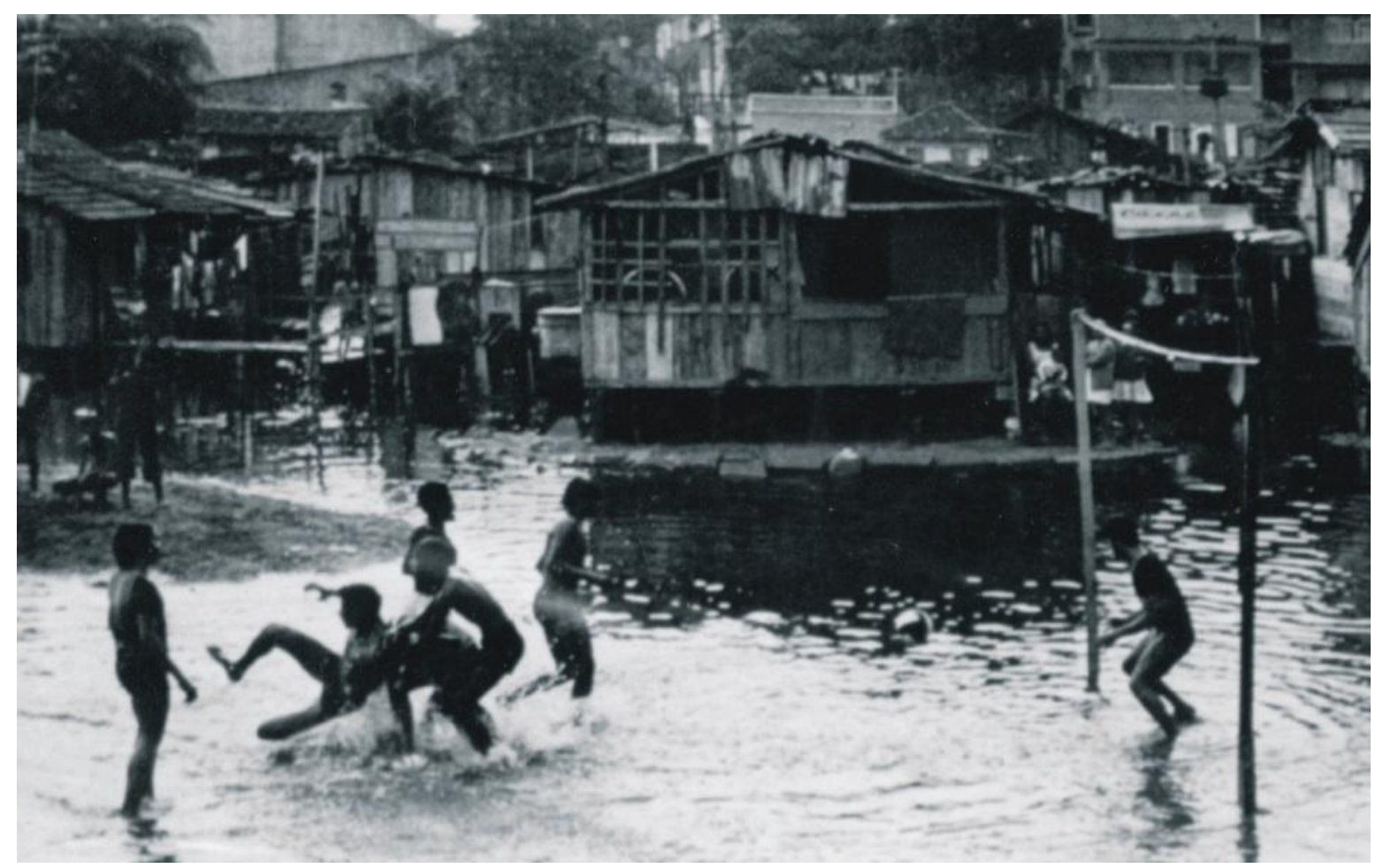

Periódico comunitario O cidadão da Maré No 51. Memórias da Maré. Archivo Dona Orosina Vieira.

Con el Proyecto Rio, los palafitos fueron sustituidos por los primeros conjuntos habitacionales dotados de infraestructuras básicas (agua, electricidad, instalaciones sanitarias y pavimento) siguiendo la lógica del progreso en la ciudad. Las favelas de Maré acompañan el crecimiento de población que se vive en las favelas de Rio de Janeiro que, según los datos del 
Instituto Brasileiro de Geografía y Estadística IBGE fue 16\% en 1980, $19 \%$ en 1990 y 22\% en 2000. ${ }^{\text {vii }}$ En la actualidad 1,3 millones de personas residen en 763 espacios populares de la ciudad.

Según el geógrafo y profesor León Diniz, ${ }^{\text {viii }}$ actualmente el conjunto de favelas de Maré, en los datos del censo del Centro de Estudios Solidarios de Maré de 2010, el conjunto tiene casi 140 mil personas, distribuidas en más 40.000 domicilios en una área aproximada de 4,3 kilómetros cuadrados divididos en 16 comunidades: el núcleo original de Maré está conformado por: Morro de Timbau (creada en 1940), Baixa do Sapateiro (creada en 1947), Parque Maré (1953), Parque Rubens Vaz (1954), Parque União (1961) y Nova Holanda (1962). Entre estas, según De Souza Silva, ${ }^{\text {ix }}$ Praia de Ramos (1962) y Nova Holanda fueron creadas por el Estado en la década de 1960 y el conjunto Marcílio Dias (1948) y el Parque Roquete Pinto (1955) creadas en el mismo período que las favelas del núcleo original. Vila do João (1982), Vila do Pinheiro (1983), Conjunto Pinheiro (1989) y Conjunto Esperança (1982) fueron creadas por el gobierno federal para ser ocupadas por antiguos moradores de las comunidades originales, principalmente los que residieron con anterioridad en los palafitos.

Nova Holanda surgió por el año de 1961 bajo el gobierno del presidente Carlos Lacerda, con la intención de ser un Centro de Habitación Provisorio para abrigar inicialmente a las familias oriundas de la Favela do Esqueleto, Praia do Pinto, Morro da Formiga y Morro do Querosene. De acuerdo con lo planificado, los moradores que fueron removidos pasarían por un proceso de preparación para después habitar en locales urbanizados, lo que nunca se hizo realidad. ${ }^{\mathrm{x}}$

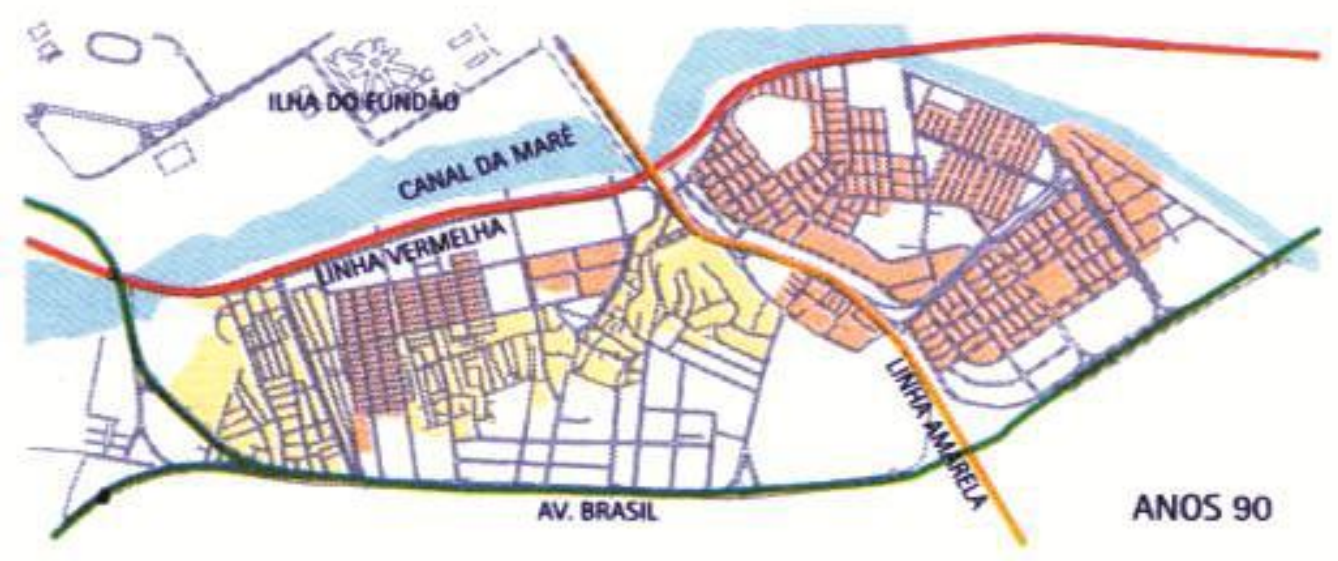

Mapa de una parte del conjunto de favelas de Maré: En naranja, comunidades del barrio construidas pro el poder público. La parte amarilla y blanca son ocupaciones realizadas por los moradores. No están en el mapa las comunidades Roquete Pinto, Praia de Ramos e Marcilio Díaz

Las favelas: Conjunto Bento Ribeiro Dantas (1989), Nova Maré (1996) y Salsa e Merengue (2000), ${ }^{\mathrm{xi}}$ fueron creadas por el poder público municipal en la década de los 90 y reúnen 
moradores provenientes de las llamadas áreas de riesgo. Cada cierto tiempo surgen nuevos asentamientos, ocupaciones de territorio que son nombrados con el ir y venir de los días y la creatividad de sus moradores, como es el caso de Mandacarú, Mclaren, Sobradinho o Marrocos; nuevas ocupaciones, resultado del aumento poblacional y la falta de eficientes políticas públicas sobre el tema de vivienda. ${ }^{\text {xii }}$

La concentración de vías férreas, edificios públicos e instalaciones industrialescomerciales hace que las fronteras entre estas comunidades sean heterogéneas, con niveles diferenciados de vecindad. La pugna entre grupos locales del narcotráfico, a su vez, tiene un fuerte papel que inhibe la circulación de los moradores entre los espacios locales. Además del narcotráfico, existe un espacio dominado por grupos a los que se les conoce como "milicia" y también por un Batallón de la Policía Militar. ${ }^{\text {xiii }}$

Según Jung (2006), la favela es una de las representaciones en la organización espacial de la metrópoli, la cual precisa ser problematizada, pues la dicotomía favela/ciudad aún produce imaginarios que tienden a marcar/reducir dichos espacios sociales de la llamada periferia de las ciudades a ser lugares de producción de violencia y crimen, lugares marginales. Dichos limites generan muros de silencio, miedo y prejuicio (Rocha, 2005), ya que además de las condiciones precarias debido a la falta de servicios básicos con la que se enfrentan las personas que tienen en dichos lugares su cotidiano, las favelas, las colonias populares o barrios de periferia en otros países de nuestra América y del mundo son vistas como un espacio de negación que representan estigmas sociales; un espacio que, en palabras de Esteves (2004) es definido socialmente como un lugar de ausencia. $^{\text {xiv }}$

¿Hacia dónde apunta esa asociación entre espacios de favela como lugares de ausencia? El hecho de que la pluralidad de el cotidiano de los moradores de espacios populares y comunidades, los espacios de vivienda de la clase trabajadora que dinamiza la ciudad, sea ignorada por los otros habitantes de las ciudades resulta en la designación de aquellos espacios como lugar de ausencia; el estigma cotidiano en las personas que viven en la favela se traduce en representaciones y manifestaciones que tensionan las posiciones, los lugares de reconocimiento de los espacios de vivienda popular y su pluralidad como espacios donde lo básico de la dignidad humana debe ser un derecho. ${ }^{\mathrm{xv}}$ Dicha tensión es una constante entre los diversos discursos sobre la favela, que históricamente se traduce en choques entre aquellos discursos, políticas públicas y sus habitantes. ${ }^{\text {xi }}$

Volvamos a Maré. A mediados de los años noventa, junto con los movimientos de colaboración comunitaria, que han sido elemento fundamental de la organización cotidiana en 
dichos espacios, ${ }^{\text {xvii }}$ comenzó un movimiento plural sobre otros lugares de producción de discurso para pensar la favela a partir de un tipo de comunicación que buscaba la visibilidad.

Según Tião Santos, uno de los creadores de la primera radio comunitaria en el municipio de Queimados, Rio de Janeiro: la radio «Novos Rumos», el movimiento de comunicación comunitaria seguía tres principios para aquellas prácticas que buscaba distinguirse de aquellas que son usadas en la comunicación llamada comercial o corporativa: sin fines de lucro, la pluralidad y la gestión democrática y colectiva. ${ }^{\text {xiii }}$ En el caso de Maré, el movimiento de comunicación comunitaria se genera a partir de diversas experiencias fundadoras: el periódico Nova Amace, Radio Maré FM, Radio Devas, TV Maré, Radio Progressiva FM y otras que constituyen el universo de comunicación comunitaria de favelas, que es el universo de la experiencia de comunicación comunitaria de la cual nos ocupamos en este análisis: el periódico $O$ cidadão da Maré. ${ }^{x i x}$

Con esos movimientos de autogestión dentro de los territorios de favela en la ciudad de Rio de Janeiro, otras formas de enunciar el territorio aparecen y se configuran continuamente. El gesto de visibilizar el cotidiano, se convirtió en un contrapunto para el discurso de ausencia.

\section{EL ENCUENTRO}

Conocí a Gizele Martins, comunicadora y coordinadora del periódico sobre el que versa este trabajo, en octubre de 2012. En el Primer Seminario de Comunicación Comunitaria en la Pontificia Universidad Católica de Rio de Janeiro PUC ${ }^{\mathrm{xx}}$, un evento organizado por ella misma y Daiane Ramos, del Departamento de Comunicación y Gestión de la Secretaría de Cultura del Estado de Rio de Janeiro. El seminario reunió varias experiencias más allá de la comunicación comunitaria, de entre las que se pueden mencionar diversas formas de narrativa sobre la ciudad, las ciudades: Proyectos de Hip Hop con adolescentes, el Museu da Pessoa de São Paulo, ${ }^{\text {xi }}$ Radio comunitaria Santa Marta, entre otros. El seminario fue una ventana hacia las múltiples experiencias con las cuales dialoga la comunicación comunitaria a partir de la visión de sus organizadoras. Ahí me dieron el número 63 del periódico. En busca de una primera entrevista para comenzar el diálogo con el periódico y su práctica, en enero de 2013 me citó la periodista, Gizele, en el conjunto de favelas de Maré.

Con el sol de las 10 de la mañana, aquél sábado bajé del autobús en la Pasarela 6 en la Avenida Brasil, esperando encontrarme con Gizele, quien es también moradora de dicho conjunto habitacional. Durante la media hora de espera, desde una de las calles frente a una guardería, cerca de una tienda de ultramarinos, observe lo que ahí ocurría: 
En las calles, hombres armados en dos esquinas; una señora pasó de la mano de un niño, los miró y siguió su camino. La señora, de unos cuarenta años, entró en la tienda, compró y después se quedó afuera, cerca de donde yo estaba, platicando con otra persona. Los hombres, arma y radios en mano, continuaban ahí. Pasó otro niño solo con dinero en la mano, cruzó un puente. El niño volvió a los 5 minutos con un cometa en las manos. Más niños y niñas atravesando las calles de tierra, radios encendidas de aquellos hombres vestidos de civil y con armas al hombro, los niños pasaban riendo y haciéndose bromas entre ellos. Yo seguía esperando. Pasaron ancianos, jóvenes, repartidores de comida, familias de tres, cuatro, cinco personas, etcétera.

Aquellas imágenes y sensaciones me recordaron al período 2010-2011 en México, en mi ciudad, el Puerto de Veracruz, pues por aquellos días, tomada en pocos meses y de forma violenta como consecuencia de las políticas y acciones de una guerra declarada al narcotráfico, el sentimiento de ciudad sitiada me ahogaba, nos ahogaba. Tiroteos, el continuo estado de alerta. Miedo, los medios de comunicación callaban informaciones y exageraban otras mientras la ciudadanía intentaba seguir con su cotidiano. ${ }^{\text {xii }}$

Aquellas imágenes y las informaciones que previamente había buscado sobre Maré y el tema favela, me hicieron también recordar cuando acompañé, con una sensación de impotencia, al Movimiento por la paz con justicia y dignidad, cuando la primera caravana organizada llegó a la ciudad de Xalapa, en septiembre de 2011. Mexicanos/as, veracruzanos/as y de otras partes del país: mujeres, jóvenes, familias que estaban ahí no solo para acompañar la manifestación en la calle, sino también para recordar a sus muertos, para no olvidar a sus familiares y amigos desaparecidos, recordarlos en su cotidiano e intentando mantenerse vivos y actuantes, resistentes. Vino también una memoria sonora: en los primeros días, en que la violencia comenzaba a ser más intensa en el Puerto de Veracruz, helicópteros pasando al ras de los techos de las casas, con la sirena prendida a media noche, la sensación colectiva de terror, de vulnerabilidad. La supresión de las historias de aquellas víctimas sin nombre: los “daños colaterales" de una guerra que la mayoría de los ciudadanos mexicanos no escogimos vivir y que aún, varios años después, han significado la desaparición y muerte de miles de personas en este país.

Pero vuelvo a la descripción del cotidiano en Maré de aquel día. Cuando, al fin, me encontré con la periodista aquel día de enero en el Conjunto Esperança y ya que estábamos en vísperas de carnaval, Gizele quería que acompañáramos a un bloco, ${ }^{\text {xiii }}$ donde ella también participaba, aquel bloco ha sido bautizado como "Se benze que dá"( se traduciría como "Persígnate que todo irá bien”), este bloco de carnaval, desde su inicio, ha tenido un sentido político, teniendo 
como objetivo, de cara a las complejidades que implica el poder ir y venir por las calles de este espacio de la ciudad, el defender el derecho a la libre circulación de los moradores en el conjunto de favelas de Maré. El bloco, por diversas razones, no salió a recorrer las calles ese día, pero, aprovechando la visita, la periodista me llevó junto con un grupo de estudiantes de la Universidad Federal Fluminense que llegó también el mismo día para conocer el proyecto del periódico y para conocer el Museo de Maré, proyecto hermano del periódico “O cidadão”.

La forma en que dicho museo narra las historias entrelazadas sobre el territorio de las favelas y las personas que las habitan es una división, un montaje en 12 tiempos. Esta composición no está dada al azar, como todo ahí; tiene su historia y está se entreteje con los primeros intentos de generar un espacio de memoria para la favela, el tiempo en que un colectivo de animosos moradores fueron recuperando fotografías antiguas de diversos temas de tal forma que, aun cuando no contaban más que con su ímpetu y creatividad, pensaban en herramientas educativas y de animación sociocultural, decidiendo crear un calendario con 12 fotografías representativas: un calendario como un dispositivo de reconocimiento de la subjetividad y el cotidiano de los habitantes de ese territorio complejo. Así fue como, al pasar el tiempo, al constituirse como la ONG Centro de Acciones Solidarias de Maré CEASM y gestionar un espacio para un museo comunitario, fue lógico pensar en esa construcción en doce momentos: Tiempo de agua, tiempo de casa, tiempo de migración, tiempo de resistencia, tiempo de trabajo, tiempo de fiesta, tiempo de mercado, tiempo de fe, tiempo de cotidiano, tiempo de infancia, tiempo de miedo y tiempo de futuro. En el centro del museo hay una reproducción de un palafito con todas las cosas que puede tener una casa: platos, planchas, mesa, cama, estufa, fotografías, etc. Todo donado por los moradores de Maré. Me encanté por la narrativa construida en dicho montaje, cada "tiempo" estaba tejido por reflexiones sobre el tema del cual hacía mención, en cada tema se leía la pluralidad, la multiculturalidad del conjunto de favelas, me encanté por la vivacidad de la memoria colectiva y el modo de ser comunicado mediante la museografía que se nos presentaba durante esa primera vez. En un estante cerca de la puerta del museo encontré algunos otros números atrasados del periódico $O$ cidadão, pues este espacio también funciona como hemeroteca, como archivo de memoria en fotografías donadas por los propios moradores, Hojeé algunos números del mismo. 


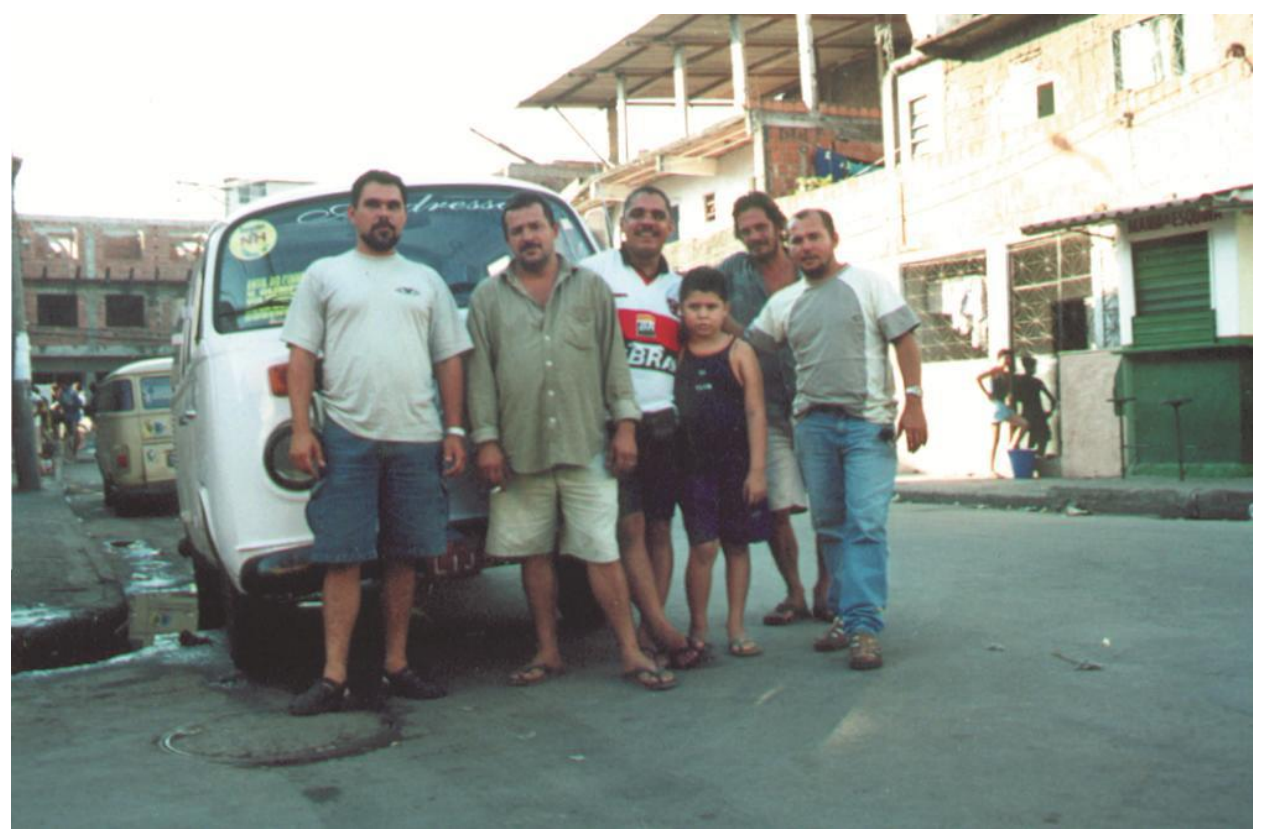

Periódico comunitario $O$ cidadão da Maré No. 15 Reportaje "Un viaje por los transportes colectivos de Maré" dice: "Las cooperativas de Combis fueron una especie de mercado de trabajo informal que emplea cerca de 300 moradores entre choferes, cobradores y fiscales (...) quien es propietario del vehículo llega a ganar cerca de 1000 reales por mes, descontado el porcentaje de la cooperativa. Ya quien trabaja como chofer gana 30 reales por día. Los cobradores, aquellos niños que abren y cierran las puertas ganan aproximadamente 10 reales diarios".

Fue una sensación de letras y vida derramándose, una sensación hasta visceral, de vida fluyendo. Había de todo: imágenes de ancianos, de casas de madera y cartón, rostros de familias, historia de calles y de sus nombres, de escuelas y edificios, de tianguis, de diversas expresiones de la fe, obreros, profesores, instituciones, colectivos, problemas de servicios básicos, historias de algunos de los personajes de las favelas, historias sobre los jóvenes de Maré, rostros de niños...historias, muchas historias del cotidiano de aquel lugar, más allá de aquellas primeras imágenes que vi en la calle, historias que tejían otros caminos para contar; muchas otras historias más allá de esa historia única contada hasta el cansancio en los noticieros vespertinos. Era Maré, eran muchas Marés narradas por algunos de sus moradores que tendían un puente narrativo para esa alteridad, en ese caso yo misma, que con avidez buscaba caminos para conocer más sobre ese mundo.

\section{COMUNICADORES COMUNITARIOS: SOBRE ENCUADRES,} ANTIESPECTACULARIDAD, LO LOCAL, EL LENGUAJE COMO MURALLA Y LA TRADUCCIÓN COMO PRÁCTICA CONTRA HEGEMÓNICA

¿Cuál es el papel de un comunicador que asume su quehacer como como comunicador comunitario? Hacemos esta pregunta desde una perspectiva que necesita considerar a los medios de comunicación, situarlos en el ámbito de las mediaciones nombradas por Barbero como procesos de 
transformación culturales donde los medios de comunicación hegemónicos nunca son el principio, pero si una pieza importante dada su condición de "creadores de sentido", de productores de una gramática que universaliza los modos de vivir (Barbero, 2003, p. 206), aquellos modos de vivir que tienen como valores al individualismo, la recompensa y la competencia (Barbero, 2010).

El comunicador comunitario busca una mirada crítica que debe contener conscientemente otras miradas, otras voces que dialogan con las problemáticas y hechos locales, asumiendo la parcialidad como principio. ${ }^{\text {xxiv }}$ Algunos testimonios sobre la experiencia del equipo del periódico $O$ Cidadão y las afirmaciones de algunos profesionales que reflexionan sobre la práctica de la comunicación popular y comunitaria en Río de Janeiro hacen colocar especial atención en cinco elementos que, en estrecha relación con las reflexiones sobre medios y mediaciones de Martin Barbero, con la sociología de las ausencias y de la sociología de las emergencias de Boaventura de Santos y las reflexiones sobre la mirada del cineasta Win Wenders, podrían dar un esbozo de lo que, a mi consideración, definen una práctica diferenciada de la comunicación comunitaria: La antiespectacularidad, la relación del comunicador con lo local, el encuadre, la reflexión sobre el lenguaje como muralla y la práctica de traducción del comunicador, gestos que constituyen las bases de una práctica de comunicación contra hegemónica.

Antiespectacularidad: Según Martin Barbero, al conectar el espectáculo con la cotidianidad, los medios de comunicación con discursos hegemónicos integran en su propio modo de operación un dispositivo paradójico de control de las diferencias, impidiendo que lo diverso nos cuestione, que cuestione nuestros mitos de desarrollo, nuestros mitos de autoridad según el cual existe un único modelo de sociedad compatible con el progreso y, por tanto, con el futuro. (Barbero, 2003, p. 263), en un movimiento al contrario, la comunicación comunitaria habla de lo pequeño, de las problemáticas cotidianas, pero también de las acciones y manifestaciones de la compleja diversidad, de experiencias de colectivos e individuos dentro de un territorio.

La relación con lo local: El entorno es fuente de información. Quien vive en un lugar carga en sí mismo un conocimiento sobre él mismo y...todo lo que sea un problema local es tema a tratar dentro de la comunicación comunitaria: por eso, dice Dioclécio Luz, todos lo que son parte de un vehículo de comunicación comunitaria deben conocer muy bien el lugar (Luz, 2004). La práctica de comunicación comunitaria tiene una estrecha relación con procesos identitarios y de animación sociocultural donde la reflexión sobre el territorio/el lenguaje/ producciones culturales y problemáticas enraizadas en los tres anteriores temas. 
EI lenguaje como muralla: La propuesta de quien piensa en el lenguaje como arena de disputa de la hegemonía para mostrar otras realidades, es analizar y cuidar de la elaboración de los discursos/enunciaciones creados en los medios alternativos, basados en que el lenguaje de los medios comerciales es la punta del iceberg de las profundas desigualdades sociales. La división de la sociedad en dos mundos, lo que Gilberto Freyre, retomado en las reflexiones sobre lenguaje del italo-brasileiro Vito Gianotti (2009), llamaría también de "barracón"(senzala) y la "casa grande", división que es producto del modelo neoliberal en las sociedades contemporáneas y que tiene raíces profundas en la tradición e historia de los medios de comunicación empresariales como fuente de información oral jerarquizada y fragmentada infinitamente en diversas experiencias de la vida económica/social/cultural de los países colonizados/de los países colonizadores.

Traducción: El trabajo de traducción, dice Boaventura de Sousa busca crear inteligibilidad, coherencia y articulación en un mundo enriquecido por tal multiplicidad y la diversidad. Cada práctica o saber decide qué es lo que se pone en contacto y con quién (Boaventura de Sousa, 2008, p. 130), teniendo como áreas de contacto, las zonas consideradas de frontera. Los contactos más promisorios son los más inclusivos, los más adecuados para profundizar el trabajo de traducción. Una serie de tareas para quien traduce son: entre qué y qué traducir, cuándo traducir, quién traduce y para qué traduce, llevando siempre en cuenta la consciencia de que hay un peligro de pensar que la historia de ese saber o de aquella práctica comienza con la propia presencia en la zona de contacto (Boaventura, 2008). Quien traduce tiene una historia y una mirada conformada por las experiencias y encuentros, por las propias indagaciones personales y concepción de la alteridad.

Encuadre: En el filme "Ventana del alma", el cineasta Win Wenders afirma:

El encuadre es algo muy extraño porque lo que está afuera es casi más (o tan importante) como lo que está dentro. Nos acostumbramos a mirar un encuadre por lo que contiene, en un cuadro, una foto o una película. Normalmente pensamos en lo que está en el interior. Pero el verdadero acto de encuadrar consiste en excluir algo (...) Hay una elección continua sobre lo que será excluido. Para mi es la parte más instigante del proceso cinematográfico. Porque a cada fotograma que se realiza, uno decide lo que hace o no hace parte de la historia, por tanto, el encuadre tiene total relación con contar la historia. ${ }^{x x v}$

Los gestos y movimientos de pensar una práctica de comunicación contra-hegemónica atraviesan continuas discusiones sobre qué mostrar, qué imágenes y textos pueden contener la fuerza de desestabilizar el discurso colocado en los medios de comunicación comerciales o hegemónicos, qué imágenes y textos pueden pasar a habitar identidades, reflexiones sobre nuestro 
tiempo. Los procesos de comunicación comunitaria convocan a pensar otras temporalidades, otros espacios, otros saberes como una afirmación de existencia y de posibilidad de la palabra, de la enunciación.

El periódico $O$ cidadão presenta una estructura abierta que se fue transformando a través de los 64 números analizados. Aquellos procesos de enunciación dejan su marca en diversos momentos de la construcción del discurso del periódico como un todo. Mirar la estructura del periódico implica también notar un modo de escribir marcado por las condiciones e identidades desde las cuales los periodistas y fotógrafos realizaron la producción de las notas, la forma en que se escogen las pautas, las redes de socialización con las cuales los periodistas se articula. Todos aquellos detalles que, según Martín Barbero Barbero (2003) implican la mediación de la escritura periodística y de la tecnología a utilizar en el diagramado de un formato específico.

\section{PERIÓDICO O CIDADÃO Y LAS OTRAS HISTORIAS DE MARÉ}

El proyecto editorial de $O$ cidadão, impreso gratuitamente debido a una política de buena vecindad con la una imprenta que tiene su sede en el Morro de Timbau, surgió con un conjunto de misiones: de integrar a las 16 favelas, rescatar elementos dispersos de las prácticas cotidianas de los moradores, divulgar y potencializar el trabajo de las diversas instituciones y movimientos sociales que participan en las comunidades, divulgar la historia de Maré y su relación con el espacio político-cultural de Rio de Janeiro y de Brasil; el periódico tiene articulaciones con diversos actores y organizaciones que son parte de movimiento de dentro y fuera de la favela, entre ellos: varias ONG, observatorios sobre diversas dinámicas sociales enfocadas en el entorno de las favelas, escuelas y guarderías públicas, el Museo de Maré, espacios deportivos, investigadores, iglesias, pequeños empresarios, asociaciones vecinales, blocos de carnaval del barrio, escuelas de samba, equipos de diversos deportes que juegan y se preparan dentro de Maré, otros proyectos de comunicación comunitaria, núcleos de investigación y formación, universidades, etc.; es decir, el periódico es parte de esa enorme diversidad que es la Maré, siendo uno de los polos que la dinamiza, articula y propone espacios para debatir y mostrar el cotidiano del mayor conjunto de favelas de la zona Leopoldina, partiendo de la idea de que la cultura es producida (y no apenas reproducida) por hombres y mujeres, niños, jóvenes, adultos y ancianos en su cotidiano.

La versión impresa del periódico tuvo en un primer momento, una periodicidad mensual/bimestral (A partir del número 59 comenzó a salir de forma más irregular, haciendo una 
pausa en su producción detenida en el año 2011 y volviendo en agosto de 2013) Tiene de 15 a 24 páginas a color impresas con las secciones fijas:

Editorial: Presenta los temas que serán desarrollados en el periódico

Sabor de Maré: Recetas presentadas por los moradores de las comunidades

Perfil: Cuenta la historia de vida y oficios de personajes específicos de la comunidad Sucedió en Maré: fiestas, asambleas, eventos y fiestas de Maré.

Página de "bosquejo" ciudadano: Espacio de libre expresión para los moradores de Maré. No representando necesariamente la opinión del periódico

Deportes: Habla de diversos eventos y competencias que suceden en Maré

Maré musical: Habla de producciones y creadores musicales de la comunidad

Cidadão zine: Espacio para los jóvenes

Entrevista: realizadas con algún especialista sobre temas educativos, ciudadanía, derechos humanos.

Cartas: Los moradores escriben para el periódico

Como la abuela decía: Tips, principalmente de cocina y vida práctica.

Publicidad: De empresas de las favelas

Naturaleza ciudadana: Tips de remedios caseros dados por los moradores consultados por los comunicadores, como contribución al periódico.

Memoria de Maré: Página hecha en colaboración con la Rede Memória Maré del CEASM y los moradores, narra diferentes momentos en la historia de las 16 favelas.

Página del CEASM: Habla de diversas acciones de la ONG.

Boca no trombone Para hablar de diversos problemas de saneamiento básico y problemas causados por las condiciones de infraestructura urbana.

Tema principal: Con cuatro páginas, es la nota principal que presenta diversas perspectivas y opiniones de moradores y especialistas. Busca hacer comparaciones con lo los medios de comunicación comerciales que hablan de algún asunto.

Además de las secciones antes señaladas, el periódico explora diversos temas sobre educación, medio ambiente, participación ciudadana, fe, seguridad, derechos humanos. Tales reportajes o notas periodísticas son decididos a partir de las reuniones de pauta del equipo, establecidas principalmente por la relación con diversos actores sociales de las favelas de Maré. En la diagramación se da énfasis a las imágenes para poder comunicarse con los moradores no 
alfabetizados, la forma de distribución también posee un diferencial (directamente, en las instituciones de la comunidad como escuelas, mercados y asociación de moradores, en charlas organizadas en la favela y encuentros con universitarios e investigadores).

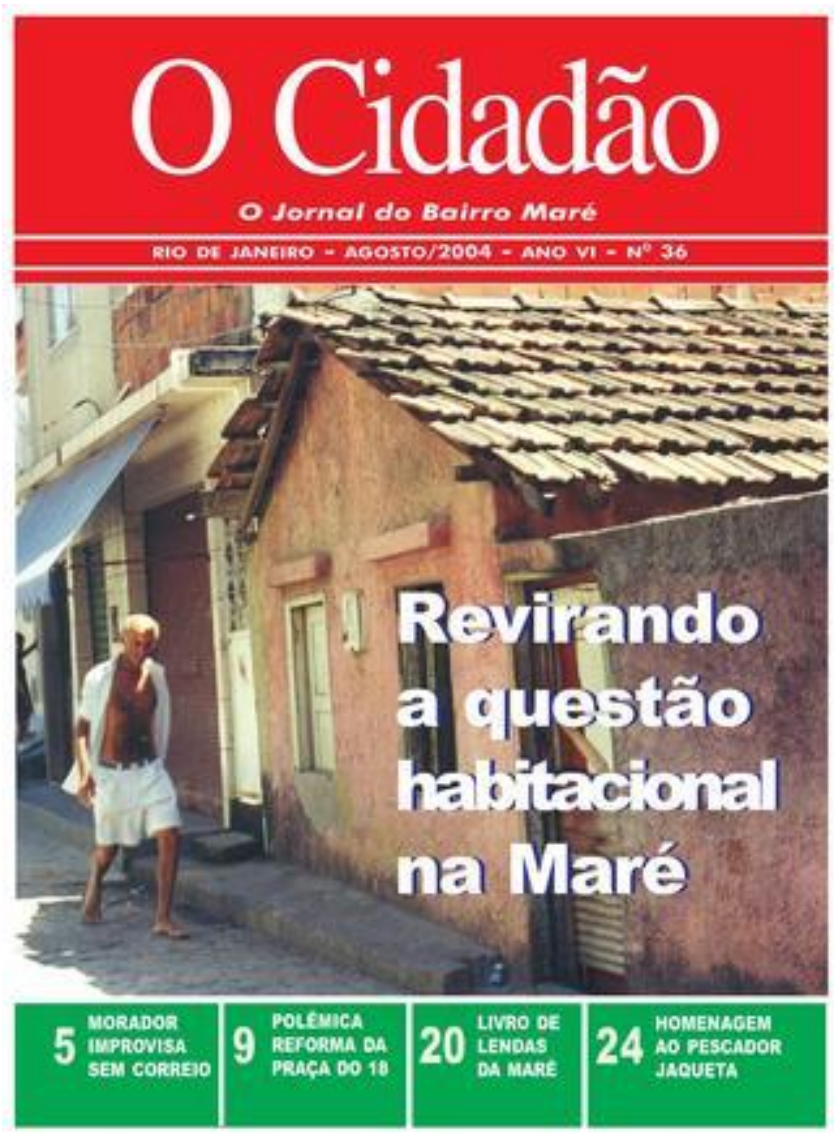

Periódico comunitario $O$ cidadão n. 36.

\section{NARRADORES DE TERRITORIO HABITADO}

La historia en los detalles, en los fragmentos, recuperada por este proyecto que comenzara en la década de los noventa como un colectivo de moradores interesados en organizarse para impulsar el desarrollo de su lugar, y pautada como contenido dentro del periódico, abre innumerables posibilidades para recontar, profundizar y romper los estereotipos que se refuerzan en diversos lugares enunciativos dentro y fuera de la favela y de la ciudad. El problema con los estereotipos, dice la escritora africana Chimamanda Adichie en su texto El peligro de la historia única, ${ }^{x x v i}$ es que pueden quebrar la dignidad de las personas que son comúnmente las protagonistas de las historias únicas contadas cientos de veces pero las historias también pueden servir para reparar esa dignidad quebrada. Dicha dignidad, las más de las veces, no está dada de manera automática para las personas que cuentan o intentan recuperan la presencia de una humanidad diversa y no basta colocar la existencia de las mismas; es preciso problematizarles uniéndolas a las 
narrativas oficiales, a las historias que, según Benjamin (cita?), son de una humanidad redimida con un pasado citable, este gesto sería un necesario contrapeso a los discursos hegemónicos sobre quién habita y circula la favela como ese otro de la ciudad.

Boaventura de Sousa Santos en su libro Gramática del tiempo habla de la necesidad de posar nuestra mirada en imágenes de la modernidad que, de tan poderosas por su profundidad, tengan la posibilidad de recolocar el sentido humano en su diversidad, en todas las ausencias que han sido atropelladas por, usando la alegoría de Walter Benjamin, aquel Angelus Novus (Benjamin, 2012, p. 63). Una de las continuas provocaciones puestas por Boaventura es la siguiente: ¿cómo construir interrogaciones/imágenes poderosas capaces de contener sentidos inagotables?, dichas imágenes son pensadas como imágenes desestabilizadoras, interrogaciones poderosas que nos impacten por su intensidad y por la concentración de energía interior que puedan recobrar nuestra capacidad de espanto, de indignación (Santos, 2008, p. 83). Nuestra sociedad de consumo, nuestra sociedad de información promueve imágenes que apelan a una totalidad del mundo que ignora las diferentes circunstancias de los pueblos, clases, sexos, regiones, etnias; el grado de credibilidad de estos textos sobre el mundo, dice aún Boaventura, consiste en presentar incansablemente una historia única sobre humanidad. En este sentido, una experiencia de comunicación comunitaria como el periódico en cuestión, responde a otra estética, a una línea discursiva que privilegia la experiencia y narrativa sobre la diversidad, sobre la experiencia de lo individual y su interrelación con su colectivo de referencia y con el territorio que habita y que le habita, imágenes que, por su propia fuerza interior, sean un contrapunto, dignidad y memoria.

Tratándose de territorio, dice Milton Santos, no basta hablar de mundialización o globalización, El territorio habitado son objetos y acciones, sinónimos de espacio humano (Santos, 2005, p. 255) en este sentido, me parece importante reflexionar sobre cómo el lugar del sujeto y su lugar en el discurso se constituyen dialógicamente. El lugar social, según Grigoletto, solo se legitima por la inscripción del sujeto en un lugar discursivo (Grigoletto, 2005, p. 6), y eso solo sucede porque existen acuerdos, formas discursivas y literarias estables para una determinada relación de alteridad, para instituir determinados lugares ocupados por los sujetos sociales. Eso, en su faceta positiva, contribuye a crear diálogos posibles y, en su faceta negativa, crea, entre otras cosas, los estereotipos, el estigma social. Los relatos presentados por el periódico $O$ cidadão, abandonan el anonimato del cotidiano y ganan potencia hacia fuera del entorno inmediato, en la medida en que son considerados como comunicables. 
Asumo la definición de Charlot, para quien el sujeto posee una historicidad, es portador de deseos y produce una interpretación de su posición social, de lo que pasa a su alrededor, teniendo al mundo como un lugar de producción de sentido, un sujeto que actúa y en esa acción afecta y es afectado en el conjunto de relaciones sociales de las cuales es parte (Charlot, 2000). Las imágenes y textos que nos presentan los periodistas-narradores de $O$ cidadão son sujetos sociales en movimiento incesante, historias que humanizan los territorios y que, como menciona Martin Barbero, son historias muchas veces en conflicto (Barbero, 2003), pero que nombran otras realidades que encuentran en este tipo de vehículos de comunicación la forma de ser enunciadas, ganan un lugar en los mapas, en los discursos sobre la ciudad. 


\section{REFERENCIAS}

AMORIM, Marilia. O pesquisador e seu outro: Bakhtin nas ciências humanas. São Paulo: Musa, 2004.

BARBERO, Jesús-Martin. Dos meios às mediações: comunicação, cultura e hegemonia. Rio de Janeiro: Editora da UFRJ. 2003.

BAKHTIN, Mikhail. Estética da criação verbal. SãoPaulo: Martins Fontes, 2000.

BENJAMIN, Walter. Papeles escogidos. 2. ed. Buenos Aires: Imago Mundi, 2011.

Obras Escolhidas: Magia e técnica, arte e política. São Paulo, 2008. v. 1, p. 108-113

2012 .

. La obra de arte en la era de su reproductibilidad técnica y otros escritos. 1. ed.: Buenos Aires: Ediciones Godot,

CHARLOT, Bernard. Da relação com o saber: elementos para uma teoria. Porto Alegre: Artemed, 2000.

DE SOUSA SANTOS, Boaventura. A gramática do tempo para uma nova cultura política. São Paulo, Cortez Editora. 2008.

DE SOUZA CHAGAS, Viktor Henrique Carneiro . Por que é cidadão o jornalista cidadão?: História das mídias e jornalismo cidadão de base comunitária na Maré. Dissertação (Mestrado em História, Política e Bens Culturais) Fundação Getúlio Vargas (FGV), 2009. Disponível em: 〈http://hdl.handle.net/10438/2676>. Acceso en: nov. 2012

GRIGOLETTO, Evandra. Do lugar social ao lugar discursivo: o imbricamento de diferentes posições sujeito. II Sead Seminario de Estudios en Analisis del UFRGS, 2005. Disponible en: http://www.ufrgs.br/analisedodiscurso/ anaisdosead/2SEAD/SIMPOSIOS/EvandraGrigoletto.pdf Acesso en:Mayo/2018

LUZ, Dioclécio, Trilha apaixonada e bem humorada do que é e de como fazer rádios comunitárias, na intenção de mudar o mundo. 2 ed.Brasilia, 2004.

NOTAS sobre el seminario Favela é cidade: as UPPs, a proposta de pacificação e a população do Rio de Janeiro, em la favela Santa Marta. 26 y 27 de novembro de 2012.

PAIVA, Rachel (org.) O retorno da comunidade: os novos caminhos do social. Rio de Janeiro: Mauad X, 2007.

PEREIRA, Rita Marisa; REZENDE Nélia (orgs.). Infância em pesquisa. Rio de Janeiro: Nau, 2012. 


\section{RESUMEN}

El siguiente texto reflexiona sobre las experiencias de alteridad en la investigación en ciencias humanas, las posibilidades y matices del dialogo intercultural dadas por un vehículo de comunicación comunitaria y la importancia del sujeto social en la construcción del discurso (en imágenes y textos) desde espacios comunicativos y de memoria no hegemónicos.

Palabras-clave. Comunicación comunitaria- alteridad- territorio .

\section{COMUNICADORES COMUNITÁRIOS COMO NARRADORES DE TERRITÓRIOS HABITADOS NA PERIFERIA DE RIO DE JANEIRO}

\section{RESUMO}

O texto seguinte reflete experiências de alteridade na pesquisa em ciências humanas, as possibilidades e matizes do dialogo intercultural geradas por um veículo de comunicação comunitária, e a importância do sujeito social na construção do discurso (em imagens e textos) desde espaços comunicativos e de memória não hegemónicos.

Palavras-chave: Comunicação comunitária-alteridade-território.

\section{COMMUNITY JOURNALISTS AS NARRATORS OF INHABITED TERRITORIES IN THE RIO DE JANEIRO OUTSKIRTS}

\section{ABSTRACT}

This text thinks about the otherness experiences in human sciences research, the intercultural dialogue possibilities and overtones provided by a community communication vehicle, and the importance of the social subject in the discourse construction (in images and texts) from non-hegemonic communication and memory spaces.

Keywords: Community /communication-otherness-territory.

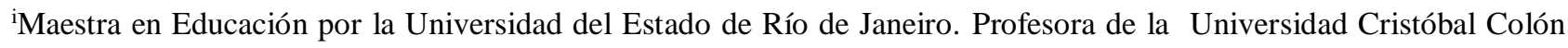
(Veracruz, México) eunicemlgc@gmail.com.

ii Investigación orientada por la Dra. Rita Ribes Pereira disponible en http://www.gpicc.pro.br. La digitalización de la mayoría de los 64 números del periódico también fue parte de esta investigación se encuentran disponibilizados para su consulta en: http://issuu.com/cidadaodamare2013.

iii Reportaje Baixa do Sapateiro uma comunidade em alta na Maré. O Cidadão, n. 14. Disponíble en <http://issuu.com/cidadaodamare2013/docs/cid14.jpg>.

iv Se denomina Zona Leopoldina a la concentración de espacios de vivienda popular: Bonsucesso, Maguinhos, Ramos, Complexo do Alemão, Olaria, Penha, Maré, Brás de Pina, Cordovil, Vigário Geral y Jardim América, barrios localizados en el perímetro de la antigua estación de ferrocarriles Rio de Janeiro Northern Railway. Fuente:Mainlines of Brazil, Developing One of the World's Largest Countries <mikes.railhistory.railfan.net/r020.html>.

v Para profundizar más en la historia de dicho territorio, se puede consultar el texto Histórias e trajetórias de um bairro chamado Maré, de Taiana Jung.

vi Una definición más clara ha sido utilizada en los estudios sobre baja renta, los cuales consideran que las personas que pertenecen a dicho grupo son las que viven con menos de US\$8 por día, de acuerdo con la UNDP (United Nations Development Programme). Esta misma definición puede ser usada para Brasil que aún presenta grandes divergencias en relación a la determinación sobre las clases sociales que pueden ser incluidas en dicha denominación. Fuente: 〈http://www.eaesp.fgvsp.br/>. 
vii Censo IBGE 2010 y la Guía de calles Maré 2012 de las ONG's locales Observatorio de Favelas y Redes da Maré.

viii Charla Mapeamento das favelas do Rio com el geógrafo y profesor del curso propedéutico comunitário Leon Diniz en el segundo curso de comunicación comunitaria organizado por el equipo de periodistas comunitarios del periódico $O$ cidadão da Maré en el Centro de Ações Solidárias da Maré CEASM Agosto 2013.

ix Jalison de Souza e Silva, Por que uns e não outros. Caminhada de jovens pobres para universidade. Edit. 7 letras. 2003.

${ }^{x}$ Reportaje 1961 Centro de habitação provisória Nova Holanda. Sección Historia da Maré. Proyecto Rede Memória. Periódico O cidadão No. 20. Disponible en: http://issuu.com/cidadaodamare2013/docs/ 20_completo.

${ }^{x i}$ Disponible: portalgeo.rio.rj.gov.br>.

xii Reportaje Moradia: um direito de poucos. Gizele Martins, en colaboración con Renata Souza. O cidadão No. 58. Disponible em: 〈http://issuu.com/cidadaodamare2013/docs/cid 58 d6bc0c324127ba〉.

xiii Datos obtenidos del documento /dossier del proyecto del Primer Comunicación comunitaria organizado por el equipo de periodistas del $O$ cidadão da Maré.

xiv Al respecto tenemos este ejemplo de una editorial del Jornal do Brasil del día 12 de diciembre de 2000 "En Maré son 38.083 casuchas (...).violencia que revelan una única cuestión: la solución en el caso de las favelas es que estas desaparezcan. Las ciudades no pueden desarrollarse con ciudadanos por la mitad, gente que no pagando impuestos, representa un peso descomunal para el resto de la sociedad (...) No pagar impuestos es apenas la primera omisión de una vida que comienza así llena de vicios. En la favela, no hay como arreglar las cosas (...)". el texto completo está disponible enhttp://hemerotecadigital.bn.br/ Jornal do Brasil - 2000 a 2009 - PRC_SPR_00009_030015, mismo que también fue referenciado em el trabajo académico de Andre Esteves Pinto $O$ cidadão : um jornal comunitário na era da globalização. Traducción de la autora.

xv "No hay derechos humanos en favelas y tribus indígenas de Brasil", dice Amnistía Internacional Agosto 2013,.disponible en: 〈http://www.bbc.co.uk/portuguese/noticias/2013/08/130810_anistia_favelas_dg.shtml>.

${ }^{\text {xvi }} \mathrm{Al}$ respecto, es interesante consultar los resultados de la investigación "Dimensiones de la ciudad: favela y asfalto", Coordinada por el Instituto Brasileiro de Análises Sociais e Econômicas (Ibase) en junio 2009 realizada a partir de 400 entrevistas con moradores del Complexo de Manguinhos (zona norte de la ciudad de Rio de Janeiro) y 413 entrevistas con moradores del "asfalto" (todas las zonas de la ciudad) donde más del $70 \%$ de los entrevistados opinan que existe prejuicio contra los moradores de favela.

xvii Un ejemplo de eso son los llamados mutirões, organizaciones colectivas realizadas por familiares y vecinos para construir viviendas en los espacios de ocupación. Referencia: Archivo Nacional (Museu da Maré) Acervo: Dona Orosina Vieira.

xviii Historia de la radio comunitária Novos Rumos: <enhttp://baixadacarioca.wordpress.com/2010/12/10/ radios-comunitarias-com-assuntos-da-comunidade/>.

${ }^{\text {xix }}$ Sobre dichas experiencias se puede consultar la investigación Porque é cidadão o jornalista cidadão: história das mídias e jornalismo cidadão de base comunitária na Maré, de Viktor Henrique Carneiro de Souza Chagas.

${ }^{\mathrm{xx}}$ Disponoble: <http://seminariocomcomunitaria.blogspot.com.br/>.

xxi Disponible: <http://www.museudapessoa.net/>. 
xxii Específicamente sobre algunas de las secuelas inmediatas de dicha guerra encontré un artículo bastante significativo "Niños, la herida más abierta de la guerra" del cual coloco un trecho: "La violencia obligó a los padres de familia a no dejar salir a sus hijos menores por temor a que estén en el lugar equivocado cuando se desate una balacera entre los cárteles rivales con el Ejército. No es un temor infundado: la Red por los Derechos de la Infancia en México (Redim) afirma que, de 2006 al primer semestre de 2010, 90 niños murieron en situaciones relacionadas con la guerra contra el narcotráfico a causa del fuego cruzado o retenes militares". Fuente: 〈http://www.sinembargo.mx/04-02-2013/512087〉.

xxiii Agrupaciones tradicionales del carnaval de calle en Rio de Janeiro.

xxiv "Nos temos sim, um lado" dizem os jornalistas Tatiana Lima, Vitor Gianotti e Gizele Martins durante as aulas do I Curso de comunicação popular de Visão favela no morro de Santa Marta em maio de 2013

xxv JANELA da Alma. Direção de João Jardim e Walter Carvalho; Produção de. Flávio R. Tambellini. Rio de Janeiro: Copacabana Filmes, 2002, 1 DVD (73min)

xxvi "Charla "El peligro de la historia única" de la novelista nigeriana Chimamanda Adichie TED Ideas Worth spreading. Disponible en: 〈http://youtu.be/EC-bh1YARsc $>$. 